Study Design This prospective, descriptive and analytical study was conducted in the maternity unit Souissi - Rabat over a one year period from January 2010 to December 2010. Obstetric and perinatal records are used in this study. A sheet filled out for each newborn comprising the socio-demographic, obstetric, nursery data, monitoring and surveillance of pregnancy, delivery as well as neonatal data, the group of dead and alive patients were compared and analyzed.

Results There were a collection of 1000 births, 971 were alive and 29 dead on which 9 were stillborn and 20 died during the first 24 hours of life. There was a singleton pregnancy in 988 cases $(98.8 \%)$, twins in 11 cases $(1.1 \%)$ and triple in 1 case $(0,1 \%)$. The statistical analysis was used to determine the prognostic factors significantly associated with the occurrence of perinatal mortality namely the Apgar $<7$ in $1 \mathrm{~min}$ and in 5 minutes $(p<0.001)$, the low birthweight $(p<0.001)$, the low gestational age $(p<0.001)$, dosage of the medication or plants during pregnancy $(p=0.01)$, the presence of congenital abnormalities $(p<0.001)$ and the multiplicity $(p=0.002)$.

\section{THE RELATIONSHIP BETWEEN BIRTHWEIGHT AND NEONATAL MORTALITY}

doi:10.1136/archdischild-2012-302724.1373

S Gatot-Irawan, A Nur Radityo, S Ariawan, MS Kosim, ER Arsita. Department of Pediatrics, Faculty of Medicine Diponegoro University - Dr. Kariadi Hospital, Semarang, Indonesia

Background Neonatal mortality rate plays a role for almost 40 per cent of under-five child mortality, around the world. An understanding about the factors related to neonatal mortality is important to prevent neonatal deaths. Birth weight was known as one of a risk factors and many studies has been conducted.

Objective To determine the relationship between birthweight and neonatal mortality.

Methods We conducted a hospital-based case control in Dr. Kariadi Hospital Semarang, Indonesia. Data were taken from medical records of babies who fulfilled inclusion criteria and admitted from January 2010 until December 2011. Neonatal mortality was defined as a death of neonates (until 28 days). Birth weight was determined at birth with same scale and categorized in to some caregories. Statistical analyses used: $\mathrm{X}^{2}$ and logistic regression.

Results We obtained 278 babies (18\% from totally babies) as a neonatal death as a Case Group and 280 babies as Control group from level 2 ward Kariadi Hospital. Between two groups respectively: Very low birth weight babies has (OR 0.5; 95\% CI; 0.2-0.8). Low birth weight babies has (OR 1.5; 95\% CI; 1.1-2.2), and appropriate birth weight has (OR 1.1; 95\% CI; 0.8-2.5).

Conclusion Low birth weight babies was a risk factor for neonatal mortality.

\section{RISK FACTORS FOR NEONATAL MORTALITY RATE}

doi:10.1136/archdischild-2012-302724.1374

MS Kosim, A Nur Radityo, T Taufan-Prasetya, S Gatot-Irawan. Department of Pediatrics, Faculty of Medicine Diponegoro University - Dr. Kariadi Hospital Semarang Indonesia, Semarang, Indonesia

Background Neonatal mortality rate plays a role for almost 40 per cent of under-five child mortality, globally. An understanding about the factors related to neonatal mortality is important to guide the development of focused and evidence-based health interventions to prevent neonatal deaths.

Objective To determine risk factor for neonatal mortality.

Methods We conducted a hospital-based case-control study in Kariadi Hospital Semarang, Indonesia. Data was taken from medical records of babies who fulfilled inclusion criteria and admitted from January 2010 until December 2011. Neonatal mortality was defined as a death of neonates (until 28 days). Risk factors were studied included: birth weight, gestation period, sepsis, type of delivery, length of stay (LOS) Statistical analyses used: $\mathrm{X}^{2}$ and logistic regression.

Results We obtained 278 (18\% from totally babies who admitted) neonatal deaths as a Case Group and 280 babies as Control group from level 2 ward Kariadi Hospital. We found between two groups prematurity has $(\mathrm{OR}=1.6$; $95 \% \mathrm{CI}: 1.1-2.6)$, low birth weight in prematurity $(\mathrm{OR}=2.0 ; 95 \% \mathrm{CI}: 1.2-3.5)$ and sepsis in prematurity $(\mathrm{OR}=2.2$; 95\% CI:1.1-4.2) while other risk factors (birth weight, type of delivery, LOS) have lower points.

Conclusion Sepsis in prematurity was a risk factor for neonatal mortality.

\section{EARLY DIAGNOSTICS OF NECROTIZING ENTEROCILITIS IN NEWBORN INFANTS UNDERWENT PERINATAL ASPHYXIA}

doi:10.1136/archdischild-2012-302724.1375

A Haciyeva. Scientific Research Institute of Pediatrics named after of K.J. Farajova, Baku, Azerbaijan

Background and Aim Defensins are antimicrobial peptides against gram positive and gram negative bacteria, fungus and viruses. The goal of the study is to reveal diagnostic fecal markers of necrotizing enterocolitis (NEC) among the various gestational age children who underwent perinatal asphyxia.

Methods The 95 newborn children have been included to study. Main group consisted of 960-4210 g birth weighing 69 infants with structural pathologies of central nervous system. Main group were classified in two subgroups: 40 preterm newborns (gestational age 30-37 weeks) with structural pathologies of central nervous system and 29 term babies with $38-40$ weeks of gestational age. 26 children (14 premature and 12 in term infants) were included in control group. Stool for analyses was taken in 3-rd, 7-th, 15-th and 30-th days of life. The concentration of human $\beta$-defensin-2 (HBD-2) was determined by immune-enzyme analysis (ELISA Kit Immune diagnostic, Bensheim, Germany).

Results In premature babies NEC development associated with the 246.2- $257.5 \mathrm{ng} / \mathrm{g}$ on 3-rd day; 173.7-206.9 ng/g on 7-th day; 161.5$188.9 \mathrm{ng} / \mathrm{g}$ on 15-th day; $155.2-167.4 \mathrm{ng} / \mathrm{g}$ on 30-th day of HBD-2 concentration. In term babies NEC developed in $246.2-268.5 \mathrm{ng} / \mathrm{g}$ on 3-rd day; 166.9-255ng/g on 7-th day, 161.5-226 ng/g on 15-th day; $155.2-208 \mathrm{ng} / \mathrm{g}$ on 30-th day of HBD-2 concentration.

Conclusion Thus, definition of fecal HBD-2 in dynamics at newborn children underwent to perinatal asphyxia allows to diagnose NEC at the initial stage of development which gives the base to begin in time treatment.

\section{PROBIOTICS FOR PREVENTION OF NECROTIZING ENTEROCOLITIS IN PRETERM VLBW NEONATES- SYSTEMATIC REVIEW OF RANDOMISED CONTROLLED TRIALS. (UPDATE 2011)}

doi:10.1136/archdischild-2012-302724.1376

1,2G Deshpande, ${ }^{3,4} \mathrm{~S}$ Rao, ${ }^{4,5}$ S Patole, ${ }^{6} \mathrm{M}$ Bulsara. ${ }^{1}$ Neonatology, Nepean Hospital Sydney; ${ }^{2}$ Nepean Clinical School, University of Sydney, Kingswood; ${ }^{3}$ Neonatology, Princess Margaret Hospital for Children, Perth, NSW; ${ }^{4}$ Centre for Neonatal Research and Education, School of Womens and Infants Health, University of Western Australia, Perth, WA; ${ }^{5}$ Neonatology, King Edward Memorial Hospital, Perth, NSW; ${ }^{6}$ University of Notre Dam, Perth, WA, Australia

Background Systematic reviews indicate significantly lower risk of NEC and mortality, and shorter time to full feeds after probiotic supplementation in preterm (Gestation $<33$ weeks) VLBW neonates. ${ }^{1-3}$ Few more RCTs have been published since then. 